\title{
Study on Storage Stability of Activated Reclaimed Rubber Powder Modified Asphalt
}

\author{
Peipei Kong ${ }^{1}$, Gang $\mathrm{Xu}^{1}{ }^{1}$, Jingyao Yang ${ }^{1}$, Xianhua Chen ${ }^{1, * \mathbb{D}}$ and Yaqin Zhu ${ }^{2}$ \\ 1 School of Transportation, Southeast University, Nanjing 211189, China; xc_kong@seu.edu.cn (P.K.); \\ xugang619@hotmail.com (G.X.); yangjingyao19@foxmail.com (J.Y.) \\ 2 Jiangsu Zhonghong Environment Technology Co., Ltd., Jiangyin 214434, China; Zhuyq@163.com \\ * Correspondence: chenxh@seu.edu.cn
}

Citation: Kong, P.; Xu, G.; Yang, J.; Chen, X.; Zhu, Y. Study on Storage Stability of Activated Reclaimed Rubber Powder Modified Asphalt. Materials 2021, 14, 4684. https:/ / doi.org/10.3390/ma14164684

Academic Editor: Gabriele Milani

Received: 20 July 2021

Accepted: 17 August 2021

Published: 19 August 2021

Publisher's Note: MDPI stays neutral with regard to jurisdictional claims in published maps and institutional affiliations.

Copyright: (c) 2021 by the authors. Licensee MDPI, Basel, Switzerland. This article is an open access article distributed under the terms and conditions of the Creative Commons Attribution (CC BY) license (https:// creativecommons.org/licenses/by/ $4.0 /)$.

\begin{abstract}
The purpose of this research was to make full use of waste lubricating by-products (LBP) and reclaimed rubber powder (RR) to modify asphalt by a one-pot approach, so as to achieve the dual purpose of solving the poor storage stability of reclaimed rubber powder modified asphalt (RRMA) and the realization of solid waste recycling. A variety of characterization techniques were performed to analyze storage stability, conventional properties and microstructure of LBPactivated reclaimed rubber powder modified asphalt (Blend). Fourier transform infrared spectroscopy illustrated that not only the chemical composition of LBP was very similar to that of asphalt, but also the activation of LBP improved the compatibility of RR with asphalt and enhanced the storage stability of Blend. Fluorescence spectrum and scanning electron microscopy results indicated that the RR without LBP activation was aggregated and dispersed as blocks in asphalt, while the LBP activated RR was uniformly dispersed in the asphalt phase. The segregation test demonstrated that Blend exhibited outstanding storage stability, in which the softening point difference was within $2.5^{\circ} \mathrm{C}$ and the segregation rate was $-0.2-0.2$. In addition, the conventional properties of Blend have been significantly improved, especially in penetration and ductility. More importantly, the short-term aging results demonstrated that, compared with RRMA, Blend possessed excellent anti-aging performance.
\end{abstract}

Keywords: lubricant by-products; reclaimed rubber powder; modified asphalt; storage stability; microstructure

\section{Introduction}

Asphalt has been widely used due to its good plasticity, cohesiveness and viscoelasticity [1,2]. However, it has exposed some defects such as easily cracking at low temperature and easily softening and flow at high temperature, which greatly limit the scope of its application [3,4]. In order to further promote the serviceability performance of asphalt, researchers have put forward a variety of improvement measures through unremitting efforts [5-9]. Among the many measures, the modification of asphalt using waste rubber powder was the most promising. It has been reported that waste rubber powder modified asphalt can not only improve the high temperature permanent deformation resistance, low temperature crack resistance, and can inhibit thermal oxygen aging, but also can improve the comfort and safety of vehicle driving, extend the service life of the pavement, and reduce traffic noise [10-14]. More importantly, the application of waste rubber in modified asphalt can not only realize the resource utilization of waste rubber but also reduce the hazards to the environment $[15,16]$.

However, the application of universal waste rubber with an integral three-dimensional network structure to modified asphalt not only increased the viscosity of modified asphalt, but also caused the separation of the rubber phase from the asphalt phase [17-20]. Surprisingly, reclaimed rubber powder, prepared by destroying the molecular cross-linking 
structure of ordinary rubber powder, modified asphalt, which effectively solved the problems of high viscosity, inferior compatibility and difficult construction of universal rubber powder modified asphalt [21-24]. The reason for this was that under the action of high temperature and high shear force, the surface of reclaimed rubber powder produces some active groups, which is conducive to the chemical bonding with asphalt, improving the storage stability of the modified asphalt [25-28]. For example, Wang et al. [26] evaluated the performance of devulcanized rubber asphalt based on rheology and environmental effects. It was found that devulcanized rubber asphalt has better storage stability and low temperature performance than vulcanized rubber asphalt. Li et al. [27] studied the physics, rheology and stability of devulcanized rubber asphalt and rubber powder asphalt and found that devulcanized rubber asphalt and rubber powder asphalt have similar physical and rheological properties, but devulcanized rubber asphalt was much better in improving storage performance. The main reason was that devulcanized rubber can integrate into asphalt to perform both chemical reaction and physical swelling while crumb rubber mainly dispersed incompatibly in asphalt. However, segregation still emerged after long-term high temperature storage [29]. The lubrication by-product (LBP) with affluent active aromatic components was a low value-added product of the lubricant production process, which was no longer suitable as raw materials of fluid catalytic cracking units or else coking units and therefore generally used as fuels [30]. It not only fritters resources but also contaminating the environment. The research literature revealed that the chemical composition of LBP was similar to asphalt, and according to the similar solubility theory, LBP could be used as excellent pre-swelling materials [31]. The rubber powder was not only activated but also its structure was expanded under the soaking and swelling of LBP [32]. To the best of our knowledge, we found that the published researches only reported the swelling effect of LBP on waste rubber powder, and there was no exhaustive information on the storage stability and microstructure of LBP-activated reclaimed rubber modified asphalt.

The objective of this work was to investigate the effect of LBP on the conventional properties, storage stability and aging performance of reclaimed rubber powder modified asphalt, as well as to explore the microstructure of LBP pretreated rubber powder modified asphalt using advanced characterization. Finally, a novel method for preparing reclaimed rubber powder modified asphalt with high storage stability was explored.

\section{Materials and Methods}

\subsection{Materials}

The lubricant by-product (LBP) used in this paper was from the lubricant manufactured (PetroChina Lanzhou Petrochemical Company, Lanzhou, China), and its properties were shown in Table 1. The asphalt in this paper was the 70\# matrix asphalt, the penetration grade of which was 70 . The 40 mesh $(425 \mu \mathrm{m})$ reclaimed rubber powder and the stabilizer were supplied by specialized manufacturers.

Table 1. Physical properties of lubricant by-products.

\begin{tabular}{lc}
\hline \multicolumn{1}{c}{ Items } & Measured Values \\
\hline Flash point $\left({ }^{\circ} \mathrm{C}\right)$ & $\geq 200$ \\
Kinematic viscosity $\left(100{ }^{\circ} \mathrm{C}, \mathrm{mm}^{2} / \mathrm{s}\right)$ & 24 \\
Aniline point $\left({ }^{\circ} \mathrm{C}\right)$ & $<32$ \\
Specific gravity $\left(20{ }^{\circ} \mathrm{C}\right)$ & 1.01 \\
Aromatics content $(\%)$ & 80 \\
Moisture content $(\%)$ & $<0.1$ \\
Sulfur content $(\%)$ & $<0.08$ \\
\hline
\end{tabular}

\subsection{Preparation of the Blend}

The Blend was prepared by the one-pot method and the flow was as shown in Figure 1. The lubricant by-products and reclaimed rubber powder were mixed in a certain ratio, 
and the mixture was activated in the oven at about $150{ }^{\circ} \mathrm{C}$ for $1 \mathrm{~h}$. Then the preheated 70\# asphalt was added to the mixture and was emulsified by high-speed shear at $180^{\circ} \mathrm{C}$ and stirred at a rate of $5000 \mathrm{r} / \mathrm{min}$ for $1 \mathrm{~h}$. Finally, the stabilizer was added and electric stirring $\left(3000 \mathrm{r} / \mathrm{min}\right.$ ) was carried out at $180{ }^{\circ} \mathrm{C}$ for $1 \mathrm{~h}$ to prepare the Blend.

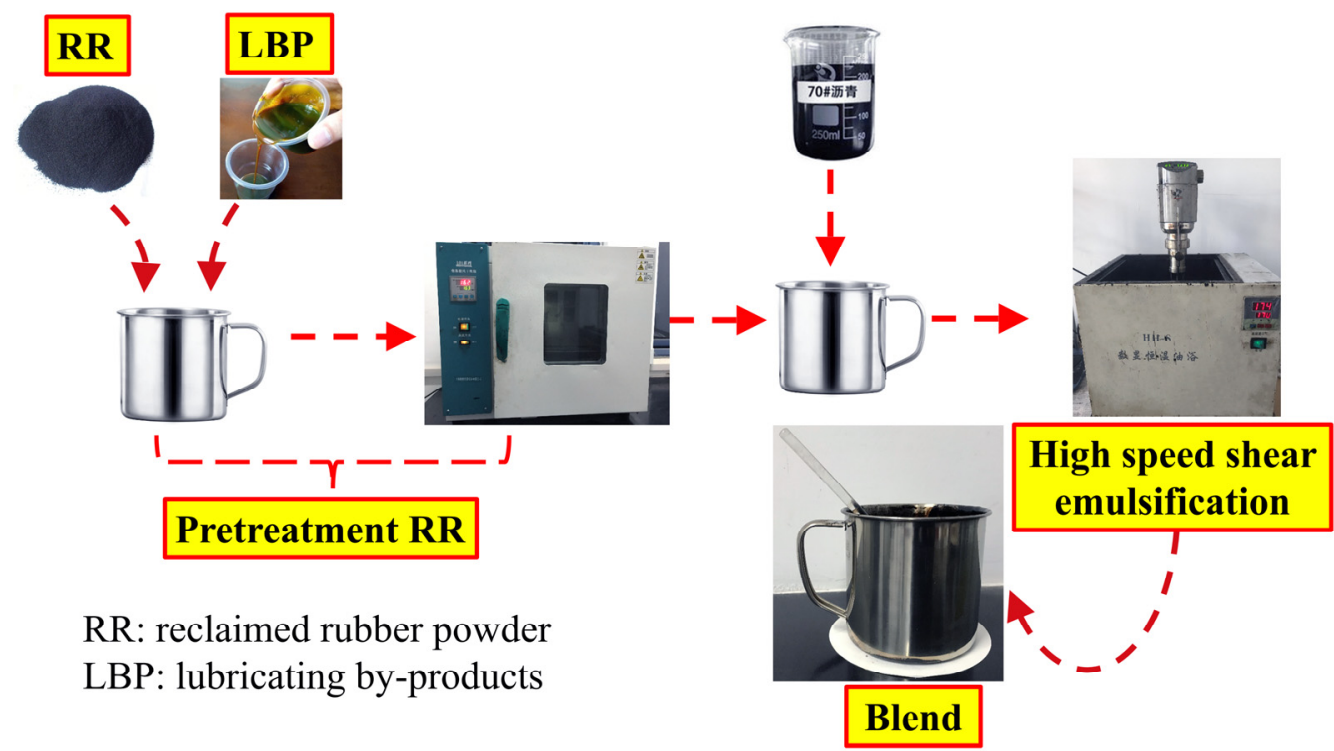

Figure 1. The preparation route of Blend.

\subsection{Measurement and Characterization}

\subsubsection{Fourier Transform Infrared Spectroscopy (FTIR)}

In order to investigate the effects of LBP, reclaimed rubber powder on the functional groups and chemical compositions of modified asphalt, the FTIR spectrometer (Nicolet iS10, Thermo Nicolet Corp., Waltham, MA, USA) was used to determine the information of the chemical structure of LBP, reclaimed rubber powder modified asphalt RRMA and Blend. The wavenumber range of the test was from 400 to $4000 \mathrm{~cm}^{-1}$.

\subsubsection{Scanning Electron Microscopy (SEM)}

The morphology of the RRMA and Blend were observed by scanning electron microscopy (SEM, S-4300, Hitachi Co., Ltd., Tokyo, Japan).

\subsubsection{Fluorescence Microscopy}

The state of reclaimed rubber powder modified asphalt and Blend were observed by fluorescence microscopy. A small molten sample was first loaded between two glass slides, which were then squashed carefully. Then, three groups of thin glass slide with sample were observed at room temperature under optical microscopy of Olympus IX71 (Tokyo, Japan).

\subsubsection{Conventional Properties}

The conventional properties, such as ductility, softening point, penetration, and viscosity were tested according to ASTM specifications [33-36]. The aging properties were conducted using a thin film oven test (TFOT) aging at $163{ }^{\circ} \mathrm{C} \pm 1{ }^{\circ} \mathrm{C}$ for $5 \mathrm{~h}$ according to ASTM specifications [37]. For each conventional property reported, at least three samples measurement were averaged.

\subsubsection{Dynamic Shear Rheometer (DSR) Tests}

Dynamic rheological properties (such as phase angle, complex modulus, and so on) of 70\# asphalt, RRMA and Blend were obtained from DSR (MCR, Anton Paar Company, Graz, 
Austria). The DSR tests temperature was $25^{\circ} \mathrm{C}$ and the angular frequency was $10 \mathrm{rad} / \mathrm{s}$. For each DSR reported, at least three samples measurement were averaged.

\subsection{Segregation Tests}

The modified asphalt was heated evenly to avoid local overheating, while stirring, injected into the sample container of the tester. Setting the storage temperature to $163^{\circ} \mathrm{C}$, leave the oven to stand for $48 \pm 1 \mathrm{~h}$ without any disturbance, the separation test tube with the bracket was gently removed from the oven and put into the low-temperature test chamber, keeping the separation test tube in an upright position, so that the modified asphalt specimens were solidified, then the separation test tube was removed from the test chamber after all curing. When the temperature of the sample was slightly softened, the sample tube was cut into three equal sections with scissors, and the top $1 / 3$ and bottom $1 / 3$ of the sample were sampled, and the softening point test and DSR were conducted. For the segregation tests, at least three samples measurement were averaged.

\section{Results and Discussion}

\subsection{FTIR Analysis}

The FTIR spectra of LBP, 70\# asphalt, RRMA and Blend were presented in Figure 2. It can be observed from Figure 2 that the characteristic peaks of LBP, 70\# asphalt, RRMA and Blend were almost the identical $\left(2926\right.$ and $2852 \mathrm{~cm}^{-1}$ : C-H aliphatic stretching; $1599 \mathrm{~cm}^{-1}$ : the aromatic $\mathrm{C}=\mathrm{C}$ stretching; $1459 \mathrm{~cm}^{-1}$ : $\mathrm{C}-\mathrm{H}$ aliphatic index bending in $\mathrm{CH}_{2} ; 1374 \mathrm{~cm}^{-1}$ : the $\mathrm{C}-\mathrm{H}$ aliphatic branched bending in $\left.\mathrm{CH}_{3}\right)$, and the only distinction was the different intensity of the characteristic peaks and the aromatic groups appearing at $787 \mathrm{~cm}^{-1}$ for LBP. Combined with the results in Table 1, it could be determined that LBP was mainly composed of aromatic compounds [30]. It was well known that aromatic compounds were an essential component of asphalt and was the dispersion medium for gum soluble asphaltenes. Therefore, the loss of aromatic components in the asphalt (e.g., swelling, oxidation) not only changed the colloidal structure of the asphalt, but also severely weakened the low-temperature performance of the modified asphalt. However, the FTIR spectra showed that LBP and asphalt possessed similar aromatic components. This fact indicated that LBP can effectively compensate for the loss of aromatic components in 70\# asphalt [32]. It can also be shown that LBP can improve the compatibility of reclaimed rubber powder and asphalt, thereby improving the storage stability of modified asphalt.

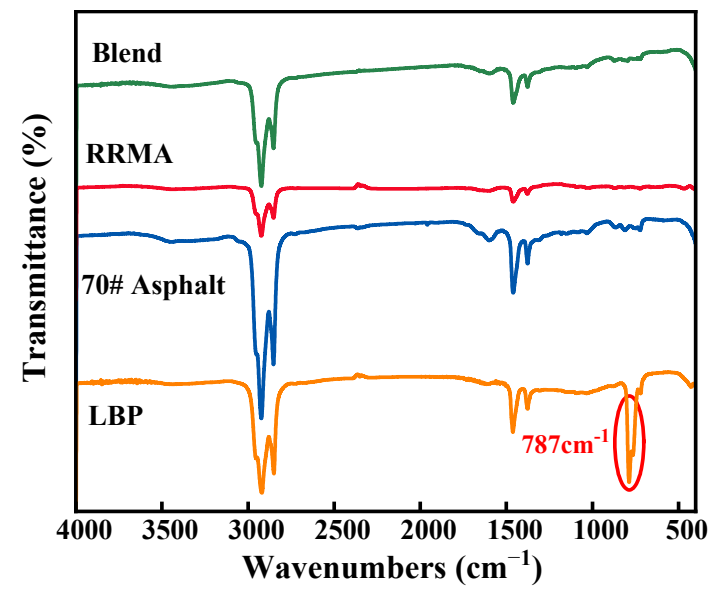

Figure 2. FTIR spectrum of LBP, 70\# asphalt, RRMA and Blend.

\subsection{Microstructure Characterization \\ 3.2.1. SEM Analysis}

In order to more clearly and intuitively observe the dispersion state of reclaimed rubber powder in asphalt, scanning electron microscopy (SEM) tests were conducted on the RRMA and Blend, the results were shown in Figure 3. It can be observed from Figure 3a that 
the surface of RRMA was uneven and possessed an obvious granular structure. The reason for this phenomenon was the low surface energy of reclaimed rubber powder, not easy to occur with the asphalt to fully swell the combination, which ultimately led to different sizes and shapes of reclaimed rubber powder particles dispersed in the asphalt [14,27]. On the contrary, the LBP-activated reclaimed rubber powder can be better dispersed in the asphalt, and there was no obvious formation of large particles. The reason for this interesting phenomenon was that the activation of LBP not only improved the surface energy of the reclaimed rubber powder, but also fully swelled the sulfur bridge structure of the reclaimed rubber powder. Therefore, the activation of LBP was beneficial to improve the compatibility of reclaimed rubber powder and asphalt, so that the reclaimed rubber powder particles were more evenly dispersed in the asphalt.

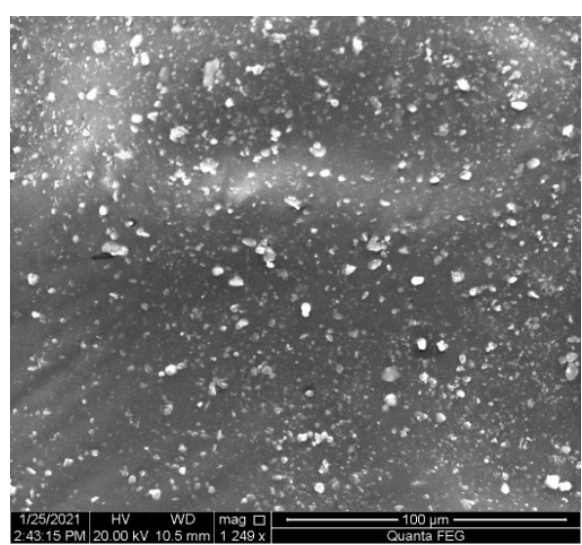

(a)

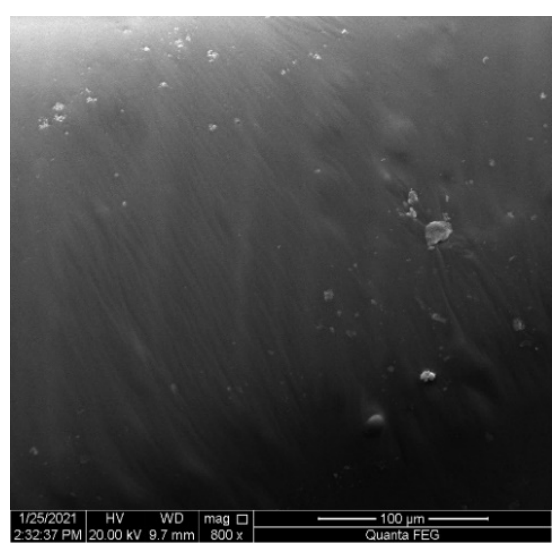

(b)

Figure 3. SEM of (a) RRMA and (b) Blend.

\subsubsection{Fluorescence Microscopy Analysis}

Fluorescence microscopy is an extremely important tool for the study of microstructures and microscopic changes. Accordingly, the composition and location of fluorescence substances in the sample could be observed and distinguished using fluorescence. As is well known, in polymer modified asphalt, when the polymer swelling in the asphalt phase is irradiated by short wavelength light, it can excite a longer wavelength fluorescence, but the asphalt phase did not emit light. More importantly, the light of this wavelength cannot damage the real morphological structure of the polymer phase in modified asphalt. Therefore, the microscopic morphology of the RRMA and Blend could be observed with fluorescence microscopy.

In this study, the fluorescence spectrum of 70\# asphalt, RRMA and Blend were shown in Figure 4. As can be seen in Figure 4a, the fluorescence spectrum of 70\# asphalt under fluorescence microscopy presented black, mainly because the asphalt phase did not emit light under fluorescence. As can be seen from Figure $4 b$, the reclaimed rubber powder particles without LBP activation were aggregated and dispersed as blocks in asphalt. At the same time, an obvious interface was observed between the rubber and asphalt, indicating that their compatibility was poor. From Figure $4 c$, it can be found that the LBP activated reclaimed rubber powder was not agglomerated, and the rubber particles were evenly dispersed in the asphalt. The main reason was that LBP weakened the interaction between the molecular chains of the reclaimed rubber powder, swelling the dense sulfur bridge structure and softening the reclaimed rubber powder sufficiently, so that the reclaimed rubber powder was evenly dispersed in the asphalt [23]. Therefore, fluorescence microscopy analysis further proved that the activation of LBP improved the storage stability and compatibility of the modified asphalt. 


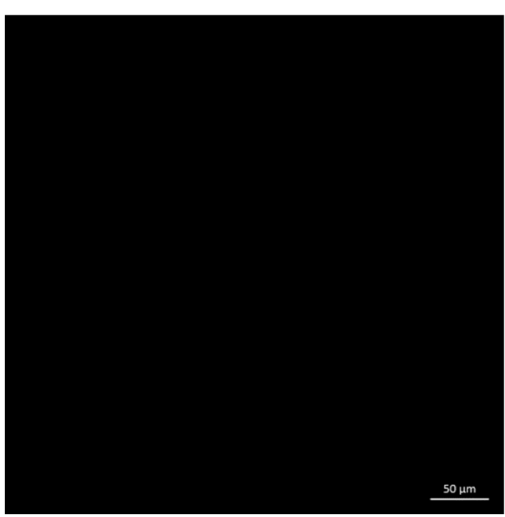

(a)

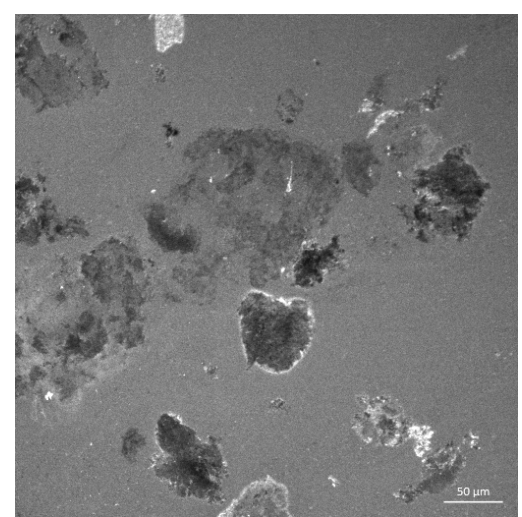

(b)

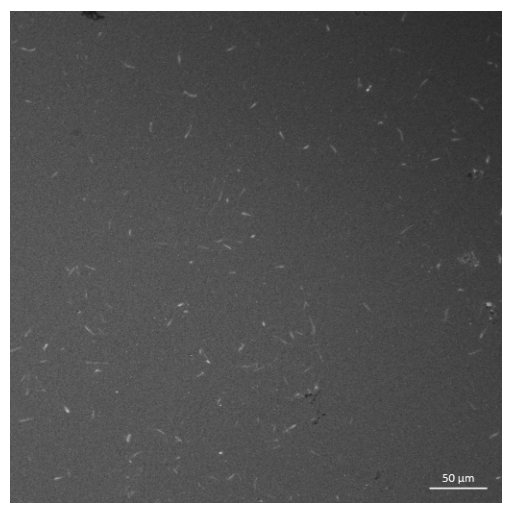

(c)

Figure 4. The fluorescence spectrum of (a) 70\# asphalt; (b) RRMA; (c) Blend.

\subsection{Storage Stability}

When the RRMA was stored at high temperature, as the density of reclaimed rubber powder was higher than the asphalt, the reclaimed rubber powder uniformly distributed in the asphalt phase was prone to sedimentation and segregation under the action of gravity. The segregation rate (as shown in Equation (1)) was used as an indicator to evaluate the storage stability of modified asphalt [28].

$$
S_{\mathrm{r}}=\left[\left(G_{\mathrm{b}} / \sin \delta_{\mathrm{b}}\right) /\left(G_{\mathrm{t}}^{*} / \sin \delta_{\mathrm{t}}\right)\right]-1
$$

where $S_{\mathrm{r}}$ is segregation rate, $G_{\mathrm{t}}{ }^{*}, G_{\mathrm{b}}{ }^{*}$ are the upper and lower complex modulus, respectively. The $\delta_{\mathrm{t}}, \delta_{\mathrm{b}}$ are the upper and lower phase angle, respectively. $G_{\mathrm{t}}^{*} / \sin \delta_{\mathrm{t}}, G_{\mathrm{b}}{ }^{*} / \sin \delta_{\mathrm{b}}$ are the rutting factor of the upper and lower samples under the storage conditions of $163{ }^{\circ} \mathrm{C}$ and $48 \pm 1 \mathrm{~h}$.

The storage stability test results of RRMA and Blend were shown in Table 2. The relationship between the segregation rate $\left(S_{\mathrm{r}}\right)$ and softening point difference were shown in Figure 5.

Table 2. DSR test results of RRMA and Blend.

\begin{tabular}{ccccccccc}
\hline $\begin{array}{c}\text { Asphalt } \\
\text { Binder }\end{array}$ & $G_{\mathbf{t}}{ }^{*} / \mathbf{k P a}$ & $G_{\mathbf{b}}{ }^{*} / \mathbf{k P a}$ & $\delta_{\mathbf{t}}$ & $\delta_{\mathbf{b}}$ & $S_{\mathbf{r}}$ & $\boldsymbol{T}_{\mathbf{t}} /{ }^{\circ} \mathbf{C}$ & $\boldsymbol{T}_{\mathbf{b}} /{ }^{\circ} \mathbf{C}$ & $\Delta \mathbf{T} /{ }^{\circ} \mathbf{C}$ \\
\hline RRMA & 1834 & 2634 & 54.4 & 48.7 & 0.60 & 64.35 & 72.25 & 7.90 \\
Blend & 2485 & 3088 & 44.3 & 52.2 & 0.17 & 77.35 & 79.45 & 2.10 \\
\hline
\end{tabular}




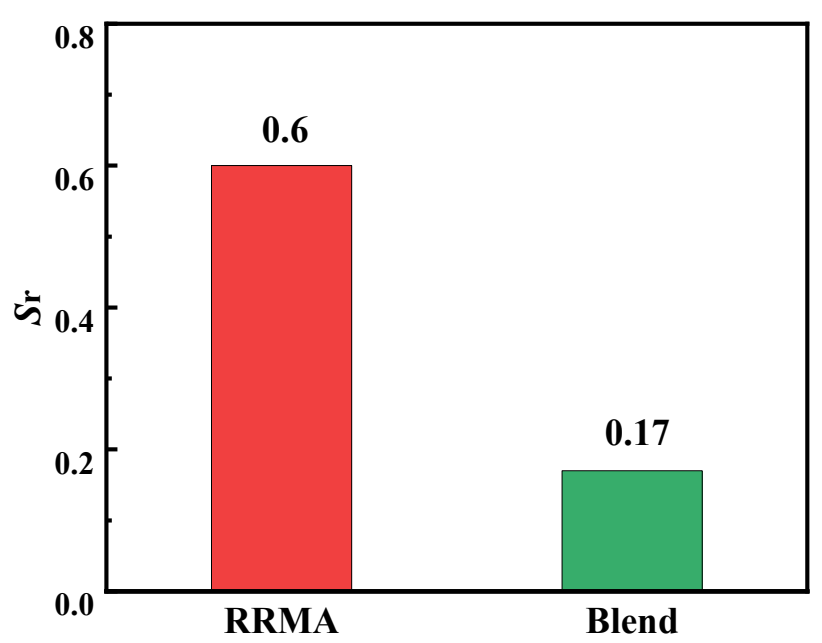

(a)

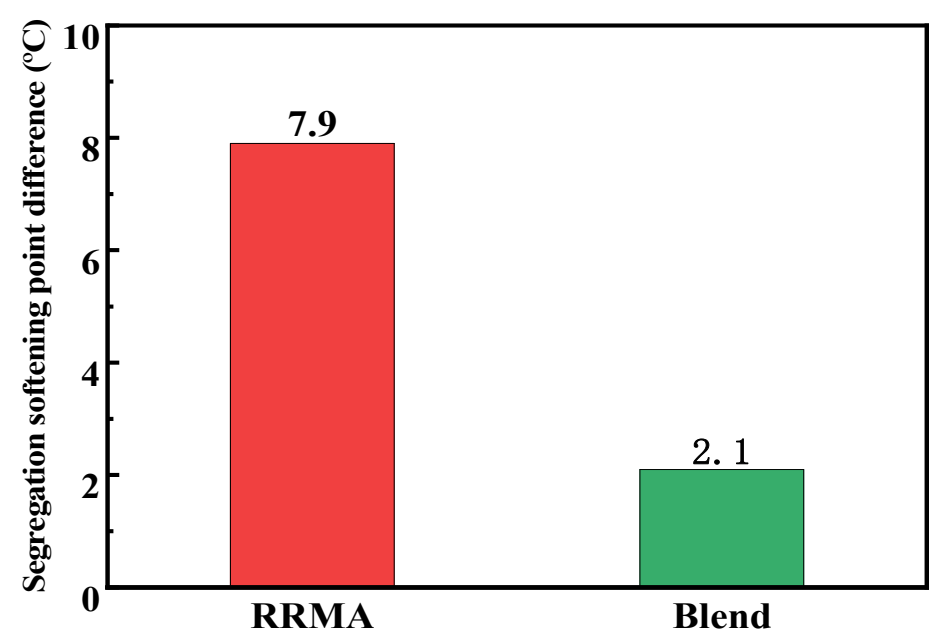

(b)

Figure 5. The (a) segregation rate (Sr); (b) segregation softening point difference of RRMA and Blend.

According to the standard of polymer modified asphalt, when the softening point difference between the upper and lower $1 / 3$ segments is less than $2.5^{\circ} \mathrm{C}$, the product is considered qualified. In addition, the storage stability of modified asphalt can also be evaluated based on the segregation rate $\left(S_{\mathrm{r}}\right)$. When $-0.2 \leq S_{\mathrm{r}} \leq 0.2$, the modified asphalt storage stability was qualified; on the contrary, it was considered unqualified. As can be seen from Table 2 and Figure 5, the LBP played an important role in improving storage stability. By adding a certain amount of LBP, the segregation softening point difference of modified asphalt could be significantly reduced, and its value was within $2.5^{\circ} \mathrm{C}$. More importantly, the $S_{\mathrm{r}}$ of modified asphalt was between $-0.2-0.2$, and the conclusions obtained from the two indicators were basically the same, which indicated that LBP-activated the reclaimed rubber powder modified asphalt possessed excellent storage stability. This phenomenon can be attributed to the fact that the LBP containing active aromatic components not only sufficiently swelled the reclaimed rubber powder, but also made the density of the LBP activated reclaimed rubber powder closer to the density of the base asphalt. As a result, the storage stability of LBP activated reclaimed rubber powder modified asphalt was improved $[23,25,28]$.

\subsection{Conventional Properties}

It can be seen from Table 3 that the conventional performance of LBP-activated reclaimed rubber powder modified asphalt was obviously improved compared with the 70\# asphalt and RRMA. Among them, the penetration of RRMA and Blend at $25^{\circ} \mathrm{C}$ was reduced compared to that of $70 \#$ asphalt, while the $5{ }^{\circ} \mathrm{C}$ ductility, softening point, and $135^{\circ} \mathrm{C}$ viscosity were increased compared to that of $70 \#$ asphalt. This indicated that the temperature sensitivity of RRMA and Blend was reduced, the high temperature performance was improved, and the low temperature ductility was increased. In addition, it can also be found that the $25^{\circ} \mathrm{C}$ penetration and $5{ }^{\circ} \mathrm{C}$ ductility of Blend were significantly higher than those of RRMA. This indicated that the activation effect of LBP improved the low temperature performance of Blend, and to some extent weakened the high temperature performance of Blend [20]. It was also worth noting that the $135^{\circ} \mathrm{C}$ viscosity of Blend was lower than of RRMA. The reason for this phenomenon may be attributed to the fact that LBP increased the proportion of aromatic components in the asphalt and weakened the asphalt-rubber interaction, thus reduced the rotational viscosity of Blend [28]. 
Table 3. Conventional properties of 70\# asphalt, RRMA and Blend.

\begin{tabular}{|c|c|c|c|}
\hline Items & 70\# Asphalt & RRMA & Blend \\
\hline Penetration $\left(25^{\circ} \mathrm{C}, 0.1 \mathrm{~mm}\right)$ & 60.6 & 50.3 & 58.8 \\
\hline Softening point $\left({ }^{\circ} \mathrm{C}\right)$ & 54.7 & 61.6 & 60.1 \\
\hline Ductility $\left(5^{\circ} \mathrm{C}, 5 \mathrm{~cm} / \mathrm{min}, \mathrm{cm}\right)$ & $>100$ & 10.1 & 11.3 \\
\hline $135^{\circ} \mathrm{C}$ viscosity $(\mathrm{Pa} \cdot \mathrm{s})$ & 0.49 & 7.2 & 6.1 \\
\hline Segregation softening point difference $\left({ }^{\circ} \mathrm{C}\right)$ & - & 7.9 & 2.1 \\
\hline \multicolumn{4}{|c|}{ Residue after TFOT } \\
\hline Residual penetration ratio $\left(25^{\circ} \mathrm{C}\right), \%$ & 74.1 & 86.5 & 88.8 \\
\hline Ductility ratio $\left(5^{\circ} \mathrm{C}\right), \%$ & - & 72.6 & 76.8 \\
\hline Softening point increment $\left({ }^{\circ} \mathrm{C}\right)$ & 3.6 & 7.0 & 5.3 \\
\hline
\end{tabular}

\subsection{Anti-Aging Performance}

Aging is the key factor affecting the service life of the asphalt pavement. In order to quantitatively evaluate the influence of LBP on the thermal oxidative aging resistance of Blend, this work measured the softening point, penetration and ductility of RRMA and Blend after TFOT test. Subsequently, the corresponding aging indexes including residual penetration ratio $\left(K_{\mathrm{p}}\right.$, as shown in Equation (2)) and softening point increment $(\Delta T$, as shown in Equation (3)), were calculated to measure the degree of modified asphalt aging.

$$
K_{\mathrm{p}}=\left(P_{2} / P_{1}\right) \times 100 \%
$$

where $K_{\mathrm{p}}$ is residual penetration ratio (\%), $P_{1}$ is the penetration of the original sample before aging $(0.1 \mathrm{~mm}), P_{2}$ is the penetration of the original sample after aging $(0.1 \mathrm{~mm})$.

$$
\Delta T=T_{2}-T_{1}
$$

where $\Delta T, T_{1}, T_{2}$ are softening point difference $\left({ }^{\circ} \mathrm{C}\right)$, softening point before aging $\left({ }^{\circ} \mathrm{C}\right)$ and softening point after aging $\left({ }^{\circ} \mathrm{C}\right)$, respectively.

As shown in Figure 6, the penetration and ductility of RRMA and Blend decreased after TFOT aging, while the corresponding softening point values of the two asphalt binders increased after aging, and the increase of RRMA was greater than that of Blend. This experimental phenomenon was consistent with the fact that short-term aging led to the hardening of asphalt binders. At the same time, the susceptibility of 70\# asphalt, RRMA and Blend to TFOT aging effects were evaluated using the aging indexes $K_{\mathrm{p}}$ and $\Delta T$. The smaller value of $K_{\mathrm{p}}$ and the larger value of $\Delta T$ indicated that the corresponding asphalt binder was more susceptible to aging and less resistant to aging. As shown in Figure 6, the $\Delta T$ of Blend was less than RRMA and 70\# asphalt. This indicated that the addition of LBP enhanced the anti-aging property of Blend [28,32].

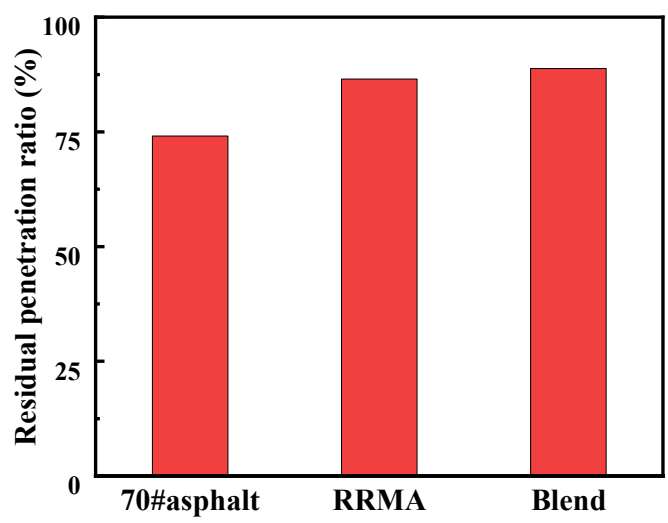

(a)

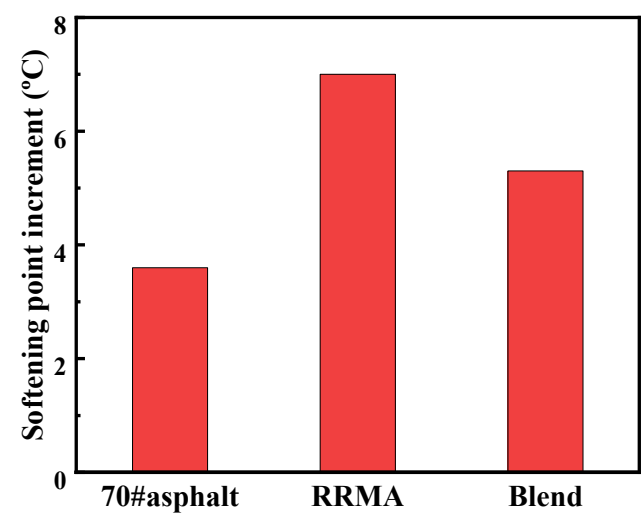

(b)

Figure 6. Aging indices of 70\# asphalt, RRMA and Blend after TFOT aging: (a) residual penetration ratio; (b) softening point increment. 


\section{Conclusions}

In this paper, modified asphalt with excellent storage properties was successfully prepared by a one-pot method using waste LBP and reclaimed rubber powder. Based on the obtained results, the following conclusions were drawn based on experiments:

1. The Fourier infrared spectroscopy demonstrated that the LBP and 70\# asphalt have similar chemical components. It indicated that LBP can improve the compatibility of reclaimed rubber powder and asphalt.

2. Fluorescence spectra and SEM revealed that the LBP activated reclaimed rubber powder can be better dispersed in asphalt, and there was no obvious agglomerated. Therefore, the activation of LBP was beneficial to improve the compatibility of reclaimed rubber powder and asphalt.

3. The segregation test indicated that the LBP activated reclaimed rubber powder modified asphalt possessed excellent storage stability, in which the softening point difference was within $2.5^{\circ} \mathrm{C}$ and the segregation rate was $-0.2-0.2$.

4. Compared with 70\# asphalt and RRMA, the conventional properties of LBP activated reclaimed rubber powder modified asphalt has been significantly improved. The activation effect of LBP improved the low temperature performance of Blend, and reduced the rotational viscosity Blend.

5. The TFOT results manifested that the anti-aging performance of LBP activated reclaimed rubber powder modified asphalt was superior to that of RRMA.

Author Contributions: Conceptualization, P.K. and X.C.; methodology, P.K.; software, G.X.; formal analysis, P.K.; investigation, J.Y. and Y.Z.; resources, Y.Z.; data curation, X.C.; writing-original draft preparation, P.K.; writing - review and editing, G.X.; visualization, J.Y.; supervision, X.C.; project administration, X.C. All authors have read and agreed to the published version of the manuscript.

Funding: This research was funded by the National Natural Science Foundation of China (No. 51778136) and Technology Research and Development Project of China Railway (No. J2019G003).

Institutional Review Board Statement: Not applicable.

Informed Consent Statement: Not applicable.

Data Availability Statement: Data is contained within the article.

Acknowledgments: The authors would like to thank staffs at National Demonstration Center for Experimental Road and Traffic Engineering Education (Southeast University), for their active contribution to this research.

Conflicts of Interest: The authors declare no conflict of interest.

\section{References}

1. Speight, J.G. Asphalt Materials Science and Technology; Butterworth-Heinemann: Oxford, UK, 2016; pp. 437-474.

2. Chen, X.; Tao, T.; Yang, G.; Yan, H.; Yang, J. Long-Lasting Waterproofing Solution for the Subgrade of High-Speed Railway in Cold Region. J. Test. Eval. 2018, 47, 1982-1994. [CrossRef]

3. Lv, S.; Xia, C.; Liu, C.; Zheng, J.; Zhang, F. Fatigue equation for asphalt mixture under low temperature and low loading frequency conditions. Constr. Build. Mater. 2019, 211, 1085-1093. [CrossRef]

4. Brasileiro, L.; Moreno-Navarro, F.; Tauste-Martínez, R.; Matos, J.; Rubio-Gámez, M.D. Reclaimed Polymers as Asphalt Binder Modifiers for More Sustainable Roads: A Review. Sustainability 2019, 11, 646. [CrossRef]

5. Li, R.; Xiao, F.; Amirkhanian, S.; You, Z.; Huang, J. Developments of nano materials and technologies on asphalt materials-A review. Constr. Build. Mater. 2017, 143, 633-648. [CrossRef]

6. Yan, W.; Ou, Y.; Xie, J.; Huang, T.; Peng, X. Study on Properties of Bone Glue/Polyurethane Composite Modified Asphalt and Its Mixture. Materials 2021, 14, 3769. [CrossRef]

7. Li, X.; Wang, Y.; Wu, Y.; Wang, H.; Wang, Q.; Zhu, X.; Fan, L. Effect of Graphene on Modified Asphalt Microstructures Based on Atomic Force Microscopy. Materials. 2021, 14, 3677. [CrossRef]

8. Liang, M.; Su, L.; Li, P.; Shi, J.; Yao, Z.; Zhang, J.; Luo, W. Investigating the Rheological Properties of Carbon Nanotubes/Polymer Composites Modified Asphalt. Materials 2020, 13, 4077. [CrossRef]

9. Ding, X.; Ma, T.; Zhang, W.; Zhang, D. Experimental study of stable crumb rubber asphalt and asphalt mixture. Constr. Build. Mater. 2017, 157, 975-981. [CrossRef] 
10. Poovaneshvaran, S.; Hasan, M.R.M.; Jaya, R.P. Impacts of recycled crumb rubber powder and natural rubber latex on the modified asphalt rheological behaviour, bonding, and resistance to shear. Constr. Build. Mater. 2020, 234, 117357. [CrossRef]

11. Gibreil, H.A.; Feng, C.P. Effects of high-density polyethylene and crumb rubber powder as modifiers on properties of hot mix asphalt. Constr. Build. Mater. 2017, 142, 101-108. [CrossRef]

12. Saberi, K.F.; Fakhri, M.; Azami, A. Evaluation of warm mix asphalt mixtures containing reclaimed asphalt pavement and crumb rubber. J. Clean Prod. 2017, 165, 1125-1132. [CrossRef]

13. Azahar, N.; Hassan, N.A.; Jaya, R.P.; Kadir, M.; Yunus, N.; Mahmud, M.Z.H. An overview on natural rubber application for asphalt modification. Int. J. Agric. For. Plant. 2016, 2, 212-218.

14. Liu, W.; Xu, Y.; Wang, H.; Shu, B.; Barbieri, D.M.; Norambuena-Contreras, J. Enhanced Storage Stability and Rheological Properties of Asphalt Modified by Activated Waste Rubber Powder. Materials 2021, 14, 2693. [CrossRef]

15. Zarei, M.; Rahmani, Z.; Zahedi, M.; Nasrollahi, M. Technical, Economic, and Environmental Investigation of the Effects of Rubber Powder Additive on Asphalt Mixtures. J. Transp. Eng. Part B Pavements 2020, 146, 04019039. [CrossRef]

16. Wang, Q.; Wang, N.; Tseng, M.; Huang, Y.; Li, N. Waste tire recycling assessment: Road application potential and carbon emissions reduction analysis of crumb rubber modified asphalt in China. J. Clean. Prod. 2020, 249, 119411. [CrossRef]

17. Li, P.; Jiang, X.; Ding, Z.; Zhao, J.; Shen, M. Analysis of viscosity and composition properties for crumb rubber modified asphalt. Constr. Build. Mater. 2018, 169, 638-647. [CrossRef]

18. Ding, Z.; Li, P.; Zhang, J.; Bing, H.; Yue, X. Analysis of viscosity test conditions for crumb-rubber-modified asphalt. Constr. Build. Mater. 2020, 245, 118454. [CrossRef]

19. Hosseinnezhad, S.; Kabir, S.F.; Oldham, D.; Mousavi, M.; Fini, E.H. Surface functionalization of rubber particles to reduce phase separation in rubberized asphalt for sustainable construction. J. Clean. Prod. 2019, 225, 82-89. [CrossRef]

20. Wang, Z.; Xu, X.; Wang, X.; Huo, J.; Guo, H.; Yang, B. Performance of modified asphalt of rubber powder through tetraethyl orthosilicate (TEOS). Constr. Build. Mater. 2021, 267, 121032. [CrossRef]

21. Sheng, Y.; Li, H.; Geng, J.; Tian, Y.; Li, Z.; Xiong, R. Production and performance of desulfurized rubber asphalt binder. Int. J. Pavement. Res. Technol. 2017, 10, 262-273. [CrossRef]

22. Liu, S.; Zhou, S.; Peng, A.; Xuan, W.; Li, W. Analysis of the performance and mechanism of desulfurized rubber and low-density polyethylene compound-modified asphalt. J. Appl. Polym. Sci. 2019, 136, 48194. [CrossRef]

23. Zhou, T.; Kabir, S.F.; Cao, L.; Luan, H.; Dong, Z.; Fini, E.H. Comparing effects of physisorption and chemisorption of bio-oil onto rubber particles in asphalt. J. Clean. Prod. 2020, 273, 123112. [CrossRef]

24. Bilema, M.; Aman, M.Y.; Hassan, N.A.; Memon, Z.A.; Omar, H.A.; Yusoff, N.I.; Milad, A. Mechanical Performance of Reclaimed Asphalt Pavement Modified with Waste Frying Oil and Crumb Rubber. Materials 2021, 14, 2781. [CrossRef]

25. Hallmark-Haack, B.L.; Hernandez, N.B.; Williams, R.C.; Cochran, E.W. Ground Tire Rubber Modification for Improved Asphalt Storage Stability. Energy Fuel. 2019, 33, 2659-2664. [CrossRef]

26. Wang, J.; Zhang, Z.; Li, Z. Performance Evaluation of Desulfurized Rubber Asphalt Based on Rheological and Environmental Effects. J. Mater. Civ. Eng. 2020, 32, 04019330. [CrossRef]

27. Li, H.; Dong, B.; Zhao, D.; Guo, P.; Zhang, J. Physical, rheological and stability properties of desulfurized rubber asphalt and crumb rubber asphalt. Arab. J. Sci. Eng. 2019, 44, 5043-5056. [CrossRef]

28. Ma, J.; Hu, M.; Sun, D.; Lu, T.; Sun, G.; Ling, S.; Xu, L. Understanding the role of waste cooking oil residue during the preparation of rubber asphalt. Resour. Conserv. Recy. 2021, 167, 105235. [CrossRef]

29. Han, L.; Zheng, M.; Wang, C. Current status and development of terminal blend tyre rubber modified asphalt. Constr. Build. Mater. 2016, 128, 399-409. [CrossRef]

30. Luo, T.; Zhang, L.; Zhang, C.; Ma, J.; Xu, Z.; Sun, X.; Zhao, S. Role of water as the co-solvent in eco-friendly processing oil extraction: Optimization from experimental data and theoretical approaches. Chem. Eng. Sci. 2018, 183, 275-287. [CrossRef]

31. Xu, S.; Hu, C.; Yu, J.; Que, Y.; Zhou, X. Performance of mixed asphalt blended with furfural extract oil and its distinction from pure asphalt. Pet. Sci. Technol. 2017, 35, 1673-1679. [CrossRef]

32. Cui, L.; Xu, J.; Cen, L.; Ren, M.; Cao, F. Molecular engineering and modification of FCC slurry oil residue for improving ageing resistance of high quality paving asphalt. Constr. Build. Mater. 2021, 299, 124234. [CrossRef]

33. ASTM. Standard Test Method for Ductility of Asphalt Materials; D113-17; ASTM International: West Conshohocken, PA, USA, 2017.

34. ASTM. Standard Test Method for Softening Point of Bitumen (Ring-and-Ball Apparatus); D36/D36M-14(2020); ASTM International: West Conshohocken, PA, USA, 2020.

35. ASTM. Standard Test Method for Penetration of Bituminous Materials; D5/D5M-20; ASTM International: West Conshohocken, PA, USA, 2020.

36. ASTM. Standard Test Method for Viscosity Determination of Asphalt at Elevated Temperatures Using a Rotational Viscometer; D4402/D4402M-15; ASTM International: West Conshohocken, PA, USA, 2015.

37. ASTM. Standard Test Method for Effects of Heat and Air on Asphaltic Materials (Thin-Film Oven Test); D1754/D1754M-20; ASTM International: West Conshohocken, PA, USA, 2020. 